\title{
Differences in gene mutations according to gender among patients with colorectal cancer
}

\author{
Yi-Jian Tsai ${ }^{1}$, Sheng-Chieh Huang ${ }^{1,2}$, Hung-Hsin Lin ${ }^{1,2}$, Chun-Chi Lin ${ }^{1,2}$, Yuan-Tzu Lan ${ }^{1,2}$, Huann-Sheng Wang ${ }^{1,2}$, \\ Shung-Haur Yang ${ }^{1,2}$, Jeng-Kai Jiang ${ }^{1,2}$, Wei-Shone Chen ${ }^{1,2}$, Tzu-chen Lin ${ }^{1,2}$, Jen-Kou Lin ${ }^{1}$ \\ and Shih-Ching Chang ${ }^{1,2^{*}}$
}

\begin{abstract}
Background: The incidence, site distribution, and mortality rates of patients with colorectal cancer differ according to gender. We investigated gene mutations in colorectal patients and wanted to examine gender-specific differences.

Methods: A total of 1505 patients who underwent surgical intervention for colorectal cancer were recruited from March 2000 to January 2010 at Taipei Veterans' General Hospital and investigated for gene mutations in K-ras, N-ras, H-ras, BRAF, loss of 18q, APC, p53, SMAD4, TGF- $\beta$, PIK3CA, PTEN, FBXW7, AKT1, and MSI.

Results: There were significant differences between male and female patients in terms of tumor location $(p<0.0001)$ and pathological stage $(p=0.011)$. The female patients had significantly more gene mutations in BRAF ( $6.4 \mathrm{vs.} 3.3 \%$, OR $1.985, p=0.006)$, TGF- $\beta$ (4.7 vs. $2.5 \%$, OR 1.887, $p=0.027$ ), and revealed a MSI-high status (14.0 vs. 8.3\%, OR 1.800, $p=0$. $001)$ than male patients. Male patients had significantly more gene mutations in $\mathrm{N}$-ras (5.1 vs. 2.3\%, OR 2.227, $p=0$. 012); however, the significance was maintained only for mutations in BRAF (OR 2.104, $p=0.038$ ), MSI-high status (OR 2. $003 p=0.001$ ), and $\mathrm{N}$-ras (OR 3.000, $p=0.010$ ) after the groups were divided by tumor site.
\end{abstract}

Conclusion: Gene mutations in BRAF, MSI-high status, and N-ras differ according to gender among patients with colorectal cancer.

Keywords: Colorectal cancer, Gender, Gene mutation

\section{Background}

Although the colorectal mucosa and colorectal cancer are morphologically identical in genders, gender-specific differences in incidence, site distribution, and mortality rates of colorectal cancer are evident. These differences were thought to be related with hormonal factors, e.g., estrogen level, or behavioral factors, e.g. nutritional habits, physical activity, and alcohol consumption [1, 2]. Previous studies revealed postmenopausal women treated with estrogen replacement therapy have a significant reduction in both risk and rate of developing colon cancer, [3] and estrogen

\footnotetext{
*Correspondence: changsc@vghtpe.gov.tw

'Division of Colon and Rectal Surgery, Department of Surgery,

Taipei-Veterans General Hospital, No 201,Sec 2, Shih-Pai Rd, 11217 Taipei,

Taiwan

${ }^{2}$ Department of Surgery, Faculty of Medicine, National Yang-Ming University, Taipei, Taiwan
}

exposure is a protective factor against microsatellites instability (MSI), while the lack of estrogen in older women increased the risk of MSI-high colon cancer [4]. Alcohol consumption may affect the risk of colorectal cancer and rectal cancer, particularly in men [5].

A recent review on the clinical and molecular characteristics of colon cancer revealed a higher incidence of right-sided colon cancer in women than in men $[6,7]$. In addition, high status MSI, CpG island methylator phenotype (CIMP), and BRAF mutations are often observed in right-sided colon cancer [1,2]. On the other hand, chromosomal instability, which is associated with 60 to $70 \%$ cases of colorectal cancer, is more often observed in left sided colon cancer and defective genes include adenomatous polyposis coli (APC), K-ras, deleted in colorectal cancer (DCC), and p53 [8]. Our goal was to

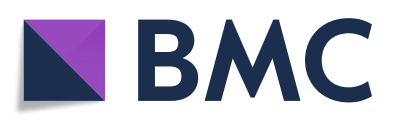

(c) The Author(s). 2018 Open Access This article is distributed under the terms of the Creative Commons Attribution 4.0 International License (http://creativecommons.org/licenses/by/4.0/), which permits unrestricted use, distribution, and reproduction in any medium, provided you give appropriate credit to the original author(s) and the source, provide a link to the Creative Commons license, and indicate if changes were made. The Creative Commons Public Domain Dedication waiver (http://creativecommons.org/publicdomain/zero/1.0/) applies to the data made available in this article, unless otherwise stated. 
identify gender-specific molecular differences, especially current known colorectal-cancer-related gene mutation, in colorectal cancer, and determine its association with the side of tumor distribution.

\section{Methods}

\section{Study setting and population}

This was a retrospective cohort study. Cases were retrieved from the database of the Division of Colorectal Surgery, Taipei Veterans General Hospital. Patients with adenocarcinoma of the colon and rectum, undergoing curative resections, were retrieved. Clinical information that had been prospectively obtained and stored in the database included age, gender, TNM stage, differentiation, location of tumor, pathological prognostic features, personal and family medical history, and follow-up conditions. The right-sided colon was defined as the colon between the cecum and the splenic flexure of the colon. The left sided colon was defined as the colon from the splenic flexure to rectum. Patients who had undergone preoperative chemo-radiotherapy, emergent operations, or who were dead within 30 days of surgery were excluded. In addition, definite germline mutations of MMR genes were noted in 30 patients, and they were also excluded.

\section{Collection of tumor tissue}

All patients gave their informed consent for inclusion before tissue collection before the operation and sample collection. The study was conducted in accordance with the Declaration of Helsinki, and the protocol was approved by the Ethic Committee of Institutional Review Board of Taipei Veterans General Hospital in Taiwan.(no. 2013-04-042B) Tumors were dissected and collected from different quadrants of the tumors and were then snap frozen in liquid nitrogen. Samples were stored at the Taipei Veterans' General Hospital Biobank.

\section{DNA isolation and quantification}

Samples were obtained from the Biobank for the study. DNA was extracted from the sample using the QIAamp DNA Tissue Kit (Qiagen, Valencia, CA, USA) according to the manufacturer's protocol. The purity and quantity of DNA were confirmed using Nanodrop ND-1000 Spectrophotometer (Thermo Scientific, Wilmington, DE, USA).

\section{MassArray-based mutation characterization}

According to hotspots found in previous studies and the Catalogue of Somatic Mutations in Cancer (COSMIC) database, The MassDetect colorectal cancer (CRC) panel (v2.0) was designed, enabling the identification of 139 mutations in 12 genes. The primers of polymerase chain reaction (PCR) and extension for the mutations were made with the MassArray Assay Design 3.1 software (Sequenom, San Diego, CA, USA). Multiplexed reactions were spotted onto SpectroCHIP II arrays, DNA fragments were resolved electrophoretically on MassArray Analyzer 4 System (Sequenom, USA), and the spectrum was analyzed (Typer 4.0 software (Sequenom, USA)) to detect mutations.

We defined a putative mutation as one with a $5 \%$ abnormal signal and then filtered it by manual review. Sanger sequencing was performed to confirm any detected mutation in BRAF, KRAS, and NRAS. The concordance was 99.1\% using MassArray and Sanger sequencing.

\section{MSI analysis}

As international criteria, we used D5S345, D2S123, BAT25, BAT26, and D17S250 as reference microsatellite markers for the determination of MSI, and obtained the primer sequences for these genes from GenBank [9] The detection of MSI was done as previously described. We defined high status MSI as samples with more than or equal to 2 MSI markers, and microsatellite stability as those with 1 or without an MSI marker.

\section{Statistical analysis}

Patient baseline characteristics, including age, gender, tumor site, tumor staging were collected. The patients were divided according to gender. Then, each gene mutation was tested by Pearson's chi-square test to find the difference between the two groups. All $p$ values are two-sided and are considered significant if they are less than .05 . The demographic data between two the groups were checked with Pearson chi-square test to identify any possible confounding factors. Data management was done using SPSS software, version 22. (IBM Corp. Armonk, NY, USA).

\section{Results}

From March 2000 to January 2010, 1505 patients were recruited from the database. The demographic data of patients are presented in Table 1.

Most of our patients were men (65.8\%), and the median age at diagnosis was 72.17 years. The tumors were most often located on left side of the colon and rectum $(73.4 \%)$, and only $6 \%$ of patients had a poorly differentiated histopathological grade. Most patients were at pathological TNM stages II (37.5\%) and III (31.4\%). The stage IV patients accounted for $17 \%$ of all patients. There were significant differences between male and female patients in terms of tumor location $(p<0.0001)$ and pathological stage $(p=0.011)$. For example, the female group had more right-sided tumors, more stage III patients, and less stage II patients. The female patients had significantly higher number of BRAF gene mutations (6.4 vs. $3.3 \%$, OR $1.985, p=0.006$ ), TGF- $\beta$ mutations (4.7 vs. $2.5 \%$, OR $1.887, p=0.027$ ), and revealed a higher MSI status (14.0 vs. $8.3 \%$, OR $1.800, p=0.001)$ than male patients. (Table 2). 
Table 1 Demographic data of patients

\begin{tabular}{|c|c|c|c|c|}
\hline & & & Men & Women \\
\hline \multicolumn{5}{|l|}{ Gender } \\
\hline Men & 990 & $65.8 \%$ & & \\
\hline Women & 515 & $34.2 \%$ & & \\
\hline Age (years) & & & & $p<0.001$ \\
\hline Median(range) & 72.17 & $28 \sim 107$ & 73.95 (28 107) & $67.20(31 \sim 95)$ \\
\hline$\leq 70$ years & 646 & $42.9 \%$ & 355 (35.9\%) & $291(56.5 \%)$ \\
\hline$>70$ years & 859 & $57.1 \%$ & $635(64.1 \%)$ & $224(43.5 \%)$ \\
\hline Pathological staging & & & & $p=0.011$ \\
\hline 1 & 212 & $14.1 \%$ & $132(13.3 \%)$ & $80(15.5 \%)$ \\
\hline$\|$ & 564 & $37.5 \%$ & 399 (40.3\%) & 165 (32.0\%) \\
\hline III & 473 & $31.4 \%$ & 291 (29.4\%) & $182(35.3 \%)$ \\
\hline IV & 256 & $17.0 \%$ & $168(17.0 \%)$ & 88 (17.1\%) \\
\hline Tumor localization & & & & $p<0.0001$ \\
\hline Right colon & 400 & $26.6 \%$ & $232(23.4 \%)$ & $168(32.6 \%)$ \\
\hline Left colon and rectum & 1105 & $73.4 \%$ & 758 (76.6\%) & $347(67.4 \%)$ \\
\hline Histopathology grade & & & & $p=0.368$ \\
\hline Well and moderately differentiated & 1417 & $94.2 \%$ & $936(94.5 \%)$ & $481(93.4 \%)$ \\
\hline Poorly differentiated & 88 & $5.8 \%$ & $54(5.5 \%)$ & $34(6.6 \%)$ \\
\hline
\end{tabular}

Male patients had significantly higher gene mutations in $\mathrm{N}$-ras (5.1 vs. $2.3 \%$, OR 2.227, $p=0.012$ ) than female patients. (Table 3 ).

We then separated the patients according to tumor sides and performed the same statistical analysis. The female patients still had a high number of gene mutations in BRAF (OR 2.104, $p=0.038$ ), MSI-high status (OR $2.003 p=0.001$ ) at right side colon, (Table 4), and the male still had a high number of gene mutations in N-ras (OR 3.000, $p=0.010$ ) (Table 5).

\section{Discussion}

Several studies have revealed that certain genetic and epigenetic differences between sexes may determine colorectal cancer risk. A recent systemic review reported that the proportion of women presenting with right-sided colon cancer, which is often at a more advanced stage at diagnosis, was higher than men [7]. Hendifar et al. reported that in patients with metastatic colorectal cancer, women were more likely to have right-sided or proximal lesion [10]. In our study, the female group was more likely to have right-sided

Table 2 Genes with higher mutation rate in female patients

\begin{tabular}{lllll}
\hline Gene mutation & F vs. M & OR & Cl 95\% & $p$ value \\
\hline BRAF & 6.4 vs. $3.3 \%$ & 1.985 & $1.211 \sim 3.256$ & 0.006 \\
TGF- $\beta$ & 4.7 vs. $2.5 \%$ & 1.887 & $1.066 \sim 3.338$ & 0.027 \\
MSI-high status & 14.0 vs. $8.3 \%$ & 1.800 & $1.286 \sim 2.519$ & 0.001
\end{tabular}

$F$ female, $M$ male, $O R$ odds ratio, $\mathrm{Cl}$ confidence interval colon cancer and more female patients were at stage III at diagnosis. This is consistent with previous studies.

Our study revealed that there is a gender-specific difference in patients with colorectal cancer regarding gene mutations of BRAF, N-ras, and high status MSI. Sporadic MSI/MMR-deficient (dMMR) colorectal cancer is associated with the BRAF V600E mutation, though its association with CIMP (CpG island methylator phenotype) [11] has been reported. In addition, an earlier study reported that female patients were 8.8 times more likely than male patients to have methylation-positive cancers [12], and previously published studies suggested that [13-15] sporadic MSI/dMMR metastatic colorectal cancer occurred more in female patients. Our study revealed that females had significantly more gene mutations than males in terms of high status MSI and BRAF which has been suggested in previous reports. Breivik et al. reported MSI tumors were more common among old women and younger men [16]. Lindblom reviewed previous study and concluded that estrogen may have a protective effect for MSI cancer in women and a possible mechanism could be an increased methylation. We have also performed further analysis toward gender, age, and MSI status in our study, no significant statistical difference was found in patients below 70 years for MSI

Table 3 Genes with higher mutation rate in male patients

\begin{tabular}{lllll}
\hline Gene mutation & M vs. F & OR & Cl 95\% & $p$ value \\
\hline N-ras & 5.1 vs. 2.3\% & 2.227 & $1.176 \sim 4.219$ & 0.012 \\
\hline
\end{tabular}

$M$ male, $F$ female, $O R$ odds ratio, $C l$ confidence interval 
Table 4 Genes with higher mutation rate in female patients after divided by tumor side

\begin{tabular}{|c|c|c|c|c|c|c|}
\hline \multirow[t]{2}{*}{ Gene mutation } & \multicolumn{3}{|c|}{ Right side } & \multicolumn{3}{|c|}{ Left side } \\
\hline & OR & Cl 95\% & $p$ value & OR & Cl 95\% & $p$ value \\
\hline BRAF & 2.104 & $1.030 \sim 4.298$ & 0.038 & 1.514 & $0.739 \sim 3.101$ & 0.254 \\
\hline TGF- $\beta$ & 1.897 & $0.895 \sim 4.020$ & 0.091 & 1.280 & $0.500 \sim 3.280$ & 0.606 \\
\hline MSI-high status & 2.003 & $1.212 \sim 3.311$ & 0.006 & 1.349 & $0.835 \sim 2.179$ & 0.220 \\
\hline
\end{tabular}

$O R$ odds ratio, $\mathrm{Cl}$ confidence interval

tumor by genders. $(p=0.334)$ And the female older than 70 years had 2.45 times risk for MSI tumors than men. $(p<0.001)$.

The approximate frequency of N-ras mutations in colorectal adenocarcinoma is 2 to $8 \%$ [17-21]. The frequency in our study was $4.1 \%$, which is consistent with previous studies; however, the significance between genders was not seen in previous reports. While some gender-specific differences were noted in our study, no other chromosomal instability-related genes demonstrated gender-specific differences.

Besides, for the interests in early-onset colorectal cancer (EOCRC) patients, we have done subgroup analysis for EOCRC. EOCRCs are disproportionately located in the distal colon, and there is a longer interval between symptoms and diagnosis [22]. In our study, 63 patients (4.2\%) are below 50 years old. Distal distribution was noted (left colon, including rectum, 77\%; rectum, 41\%), and there was a trend that increased incidence rectal cancer in more men than in women, but there is no statistical significance $(p=0.124)$.

Due to retrospective design and single center data, the study has its inherited limitation. Our databases did not query menopausal status, history of hormone replacement therapy, or contraceptive use; therefore, this limited our ability to investigate its interaction with our findings.

\section{Conclusions}

Gene mutations in high status MSI, BRAF, and N-ras differ according to gender among patients with colorectal cancer. No other chromosomal instability-related genes demonstrated gender-specific differences. Hormone status may play role in the development and pathogenesis of colorectal cancer and warrant further studies to determine it.

Table 5 Genes with higher mutation rate in male patients after divided by tumor side

\begin{tabular}{|c|c|c|c|c|c|c|}
\hline \multirow{2}{*}{$\begin{array}{l}\text { Gene } \\
\text { mutation }\end{array}$} & \multicolumn{3}{|c|}{ Right side } & \multicolumn{3}{|c|}{ Left side } \\
\hline & OR & Cl 95\% & $p$ value & OR & Cl 95\% & $p$ value \\
\hline N-ras & 1.472 & $0.541 \sim 4.000$ & 0.446 & 3.000 & $1.256 \sim 7.142$ & 0.010 \\
\hline
\end{tabular}

$O R$ odds ratio, $\mathrm{Cl}$ confidence interval

\section{Abbreviations}

APC: Adenomatous polyposis coli; Cl: Confidence interval; CIMP: CpG island methylator phenotype; CRC: Colorectal cancer; DCC: Deleted in colorectal cancer; MSI: Microsatellite instability; PCR: Polymerase chain reaction; PI3K: Phosphoinositol-3-kinase; TGF- $\beta$ : Transforming growth factor beta; TNM: Tumor-node-metastasis

\section{Funding}

This research was funded by grants from the Taipei Veterans General Hospital, (V101E2-005) Department of Health, Taipei City Government (10401-62-031; 10601-62-059), and Ministry of Science and Technology, Taiwan (105-2314-B-075-010 -MY2).

\section{Availability of data and materials}

Please contact the corresponding author for data requests.

\section{Authors' contributions}

Y-JT analyzed the data and drafted the manuscript. S-CH, H-HL, C-CL, Y-TL, HSW, S-HY, W-SC, J-KJ, T-CL, and J-KL carried out collecting patients' records and samples. S-CC conceived and designed the experiments and completed the manuscript. All authors read and approved the final manuscript.

Ethics approval and consent to participate

The study protocol was approved by Ethic Committee of Institutional Review Board of Taipei Veterans General Hospital in Taiwan.

\section{Consent for publication}

Not applicable

\section{Competing interests}

The authors declare that they have no competing interests.

\section{Publisher's Note}

Springer Nature remains neutral with regard to jurisdictional claims in published maps and institutional affiliations.

Received: 12 January 2018 Accepted: 25 June 2018

Published online: 05 July 2018

\section{References}

1. DeCosse JJ, Ngoi SS, Jacobson JS, Cennerazzo WJ. Gender and colorectal cancer. Eur J Cancer Prev. 1993;2:105-15.

2. Kim SE, Paik HY, Yoon H, Lee JE, Kim N, Sung MK. Sex- and gender-specific disparities in colorectal cancer risk. World J Gastroenterol. 2015;21:5167-75.

3. Rossouw JE, Anderson GL, Prentice RL, LaCroix AZ, Kooperberg C, Stefanick ML, Jackson RD, Beresford SA, Howard BV, Johnson KC, et al. Risks and benefits of estrogen plus progestin in healthy postmenopausal women: principal results from the Women's Health Initiative randomized controlled trial. JAMA. 2002;288:321-33.

4. Slattery ML, Potter JD, Curtin K, Edwards S, Ma KN, Anderson K, Schaffer D, Samowitz WS. Estrogens reduce and withdrawal of estrogens increase risk of microsatellite instability-positive colon cancer. Cancer Res. 2001;61:126-30.

5. Longnecker MP. A case-control study of alcoholic beverage consumption in relation to risk of cancer of the right colon and rectum in men. Cancer Causes Control. 1990;1:5-14.

6. Benedix F, Kube R, Meyer F, Schmidt U, Gastinger I, Lippert H, Colon/rectum carcinomas study G. Comparison of 17,641 patients with right- and leftsided colon cancer: differences in epidemiology, perioperative course, histology, and survival. Dis Colon Rectum. 2010;53:57-64. 
7. Hansen IO, Jess P. Possible better long-term survival in left versus rightsided colon cancer - a systematic review. Dan Med J. 2012;59:A4444.

8. Missiaglia E, Jacobs B, D'Ario G, Di Narzo AF, Soneson C, Budinska E, Popovici V, Vecchione L, Gerster S, Yan P, et al. Distal and proximal colon cancers differ in terms of molecular, pathological, and clinical features. Ann Oncol. 2014;25:1995-2001.

9. Genbank. https://blast.ncbi.nlm.nih.gov/Blast.cgi, accessed on 24 June 2014.

10. Hendifar A, Yang D, Lenz F, Lurje G, Pohl A, Lenz C, Ning Y, Zhang W, Lenz $\mathrm{HJ}$. Gender disparities in metastatic colorectal cancer survival. Clin Cancer Res. 2009;15:6391-7.

11. Colle R, Cohen R, Cochereau D, Duval A, Lascols O, Lopez-Trabada D, Afchain P, Trouilloud I, Parc Y, Lefevre JH, et al. Immunotherapy and patients treated for cancer with microsatellite instability. Bull Cancer. 2017; 104:42-51.

12. Wiencke JK, Zheng S, Lafuente A, Lafuente MJ, Grudzen C, Wrensch MR, Miike R, Ballesta A, Trias M. Aberrant methylation of p16INK4a in anatomic and gender-specific subtypes of sporadic colorectal cancer. Cancer Epidemiol Biomark Prev. 1999;8:501-6.

13. Cohen R, Buhard O, Cervera P, Hain E, Dumont S, Bardier A, Bachet JB, Gornet JM, Lopez-Trabada D, Dumont S, et al. Clinical and molecular characterisation of hereditary and sporadic metastatic colorectal cancers harbouring microsatellite instability/DNA mismatch repair deficiency. Eur J Cancer. 2017;86:266-74.

14. Tran B, Kopetz S, Tie J, Gibbs P, Jiang ZQ, Lieu CH, Agarwal A, Maru DM, Sieber O, Desai J. Impact of BRAF mutation and microsatellite instability on the pattern of metastatic spread and prognosis in metastatic colorectal cancer. Cancer. 2011;117:4623-32.

15. French AJ, Sargent DJ, Burgart LJ, Foster NR, Kabat BF, Goldberg R, Shepherd L, Windschitl HE, Thibodeau SN. Prognostic significance of defective mismatch repair and BRAF V600E in patients with colon cancer. Clin Cancer Res. 2008;14:3408-15.

16. Breivik J, Lothe RA, Meling Gl, Rognum TO, Borresen-Dale AL, Gaudernack G. Different genetic pathways to proximal and distal colorectal cancer influenced by sex-related factors. Int J Cancer. 1997;74:664-9.

17. Cercek A, Braghiroli Ml, Chou JF, Hechtman JF, Kemeny N, Saltz L, Capanu M, Yaeger R. Clinical features and outcomes of patients with colorectal cancers harboring NRAS mutations. Clin Cancer Res. 2017:23:4753-60

18. Scott AJ, Lieu CH, Messersmith WA. Therapeutic approaches to RAS mutation. Cancer J. 2016;22:165-74.

19. Schirripa M, Cremolini C, Loupakis F, Morvillo M, Bergamo F, Zoratto F Salvatore L, Antoniotti C, Marmorino F, Sensi E, et al. Role of NRAS mutations as prognostic and predictive markers in metastatic colorectal cancer. Int J Cancer. 2015;136:83-90.

20. Vaughn CP, Zobell SD, Furtado LV, Baker CL, Samowitz WS. Frequency of KRAS, BRAF, and NRAS mutations in colorectal cancer. Genes Chromosomes Cancer. 2011;50:307-12.

21. Irahara N, Baba Y, Nosho K, Shima K, Yan L, Dias-Santagata D, lafrate AJ, Fuchs CS, Haigis KM, Ogino S. NRAS mutations are rare in colorectal cancer. Diagn Mol Pathol. 2010;19:157-63.

22. Patel SG, Ahnen DJ. Colorectal Cancer in the Young. Curr Gastroenterol Rep. 2018;20:15. https://doi.org/10.1007/s11894-018-0618-9.

\section{Ready to submit your research? Choose BMC and benefit from:}

- fast, convenient online submission

- thorough peer review by experienced researchers in your field

- rapid publication on acceptance

- support for research data, including large and complex data types

- gold Open Access which fosters wider collaboration and increased citations - maximum visibility for your research: over $100 \mathrm{M}$ website views per year

At BMC, research is always in progress.

Learn more biomedcentral.com/submissions 